\title{
The Inhibition Effect of a Novel Mannich Base on the Corrosion of A3 Mild Steel in 1.0 M Hydrochloric Acid Solution
}

\author{
Juan Wang ${ }^{1}$, Shi-Ai Xu ${ }^{1,2, *}$ \\ ${ }^{1}$ Shanghai Key Laboratory of Advanced Polymeric Materials, School of Materials Science and \\ Engineering, East China University of Science and Technology, Shanghai 200237, China \\ 2 The Chemical Engineering College of Qinghai University, Xining 810016, China \\ *E-mail: saxu@ecust.edu.cn
}

doi: $10.20964 / 110402621$

Received: 21 November 2015 / Accepted: 28 January 2016 / Published: 1 March 2016

\begin{abstract}
A novel inhibitor, 2,6-Dichloro-3-fluoroacetophenonalamine (DFAPA), was synthesized by the Mannich reaction between ethylenediamine, paraformaldehyde and 2,6-Dichloro-3-fluoroacetophenone (DFAP), and its inhibition effect on the corrosion of A3 mild steel (MS) in 1.0 M hydrochloric acid solution was examined by weight loss, potentiodynamic polarization, electrochemical impedance spectroscopy (EIS) and scanning electron microscopy (SEM). The inhibition efficiency (\%IE) of DFAPA increases with its concentration. The Tafel curves show that DFAPA behaves as a mixed-type inhibitor, and the EIS results indicate that the charge-transfer resistance $\left(R_{\mathrm{ct}}\right)$ increases with the concentration of DFAPA. With increasing DFAPA concentration, the apparent activation energy $\left(E_{\mathrm{a}}\right)$ for the MS dissolution decreased slightly, which could be due to the chemisorption of DFAPA onto the metal surface. In addition, the adsorption of DFAPA on the A3 MS surface obeys Langmuir adsorption isotherm.
\end{abstract}

Keywords: mild steel, Mannich base, weight loss, EIS, acid inhibition

\section{FULL TEXT}

(C) 2016 The Authors. Published by ESG (www.electrochemsci.org). This article is an open access article distributed under the terms and conditions of the Creative Commons Attribution license (http://creativecommons.org/licenses/by/4.0/). 